\title{
Blood pressure levels post mechanical thrombectomy and outcomes in non-recanalized large vessel occlusion patients
}

\author{
Nitin Goyal, ${ }^{1}$ Georgios Tsivgoulis, ${ }^{1,2}$ Abhi Pandhi, ${ }^{1}$ Kira Dillard, ${ }^{1}$ Diana Alsbrook, ${ }^{1}$ \\ Jason J Chang, ${ }^{3}$ Balaji Krishnaiah, ${ }^{1}$ Christopher Nickele, ${ }^{4}$ Daniel Hoit, ${ }^{4}$ \\ Khalid Alsherbini, ${ }^{1}$ Andrei V Alexandrov, ${ }^{1}$ Adam S Arthur, ${ }^{4}$ Lucas Elijovich ${ }^{1,4}$
}

'Department of Neurology, University of Tennessee Health Science Center, Memphis, Tennessee, USA

${ }^{2}$ Second Department of Neurology, Attikon University Hospital, School of Medicine, National and Kapodistrian University of Athens, Athens, Greece

${ }^{3}$ Medstar Washington Hospital Medical Center, Washington, District of Columbia, USA

${ }^{4}$ Department of Neurosurgery, University of Tennessee Health Science Center, SemmesMurphey Neurologic and Spine Clinic, Memphis, Tennessee, USA

\section{Correspondence to}

Dr Nitin Goyal, Department of Neurology, University of Tennessee Health Science Center, Memphis, TN 38163, USA; ngoyal@uthsc.edu

The study findings were partly presented at the Annual Meeting of the Society of Neurocritical Care, 2017.

Received 21 October 2017 Revised 21 December 2017 Accepted 28 December 2017 Published Online First 11 January 2018
Check for updates

To cite: Goyal N,

Tsivgoulis G, Pandhi A, et al. J Neurolntervent Surg

2018;10:925-931.

\section{ABSTRACT}

Objective Permissive hypertension may benefit patients with non-recanalized large vessel occlusion (nrLVO) post mechanical thrombectomy (MT) by maintaining brain perfusion. Data evaluating the impact of post-MT blood pressure (BP) levels on outcomes in nrLVO patients are scarce. We investigated the association of the post-MT BP course with safety and efficacy outcomes in nrLVO. Methods Hourly systolic BP (SBP) and diastolic BP (DBP) values were prospectively recorded for 24 hours following MT in consecutive nrLVO patients. Maximum, minimum, and mean BP levels were documented. Threemonth functional independence (FI) was defined as modified Rankin Scale (mRS) scores of $0-2$.

Results A total of $88 \mathrm{nrLVO}$ patients were evaluated post MT. Patients with FI had lower maximum SBP $(160 \pm 19 \mathrm{mmHg}$ vs $179 \pm 23 \mathrm{mmHg} ; P=0.001)$ and higher minimum SBP levels $(119 \pm 12 \mathrm{mmHg}$ vs $108 \pm 25 \mathrm{mmHg}$; $\mathrm{P}=0.008)$. Maximum SBP $(183 \pm 20 \mathrm{mmHg}$ vs $169 \pm 23 \mathrm{mmHg} ; P=0.008)$ and DBP levels $(105 \pm 20 \mathrm{mmHg}$ vs $89 \pm 18 \mathrm{mmHg} ; P=0.001)$ were higher in patients who died at 3 months while minimum SBP values were lower $(102 \pm 28 \mathrm{mmHg}$ vs $115 \pm 16 \mathrm{mmHg}$; $\mathrm{P}=0.007)$. On multivariable analyses, both maximum SBP (OR per $10 \mathrm{mmHg}$ increase: $0.55,95 \% \mathrm{Cl} 0.39$ to 0.79 ; $\mathrm{P}=0.001$ ) and minimum SBP (OR per $10 \mathrm{mmHg}$ increase: $1.64,95 \% \mathrm{Cl} 1.04$ to $2.60 ; P=0.033$ ) levels were independently associated with the odds of FI. Maximum DBP (OR per $10 \mathrm{mmHg}$ increase: $1.61 ; 95 \% \mathrm{Cl} 1.10$ to 2.36; $P=0.014)$ and minimum SBP (OR per $10 \mathrm{mmHg}$ increase: $0.65,95 \% \mathrm{Cl} 0.47$ to $0.90 ; P=0.009$ ) values were independent predictors of 3-month mortality. Conclusions Our study demonstrates that wide BP excursions from the mean during the first 24 hours post MT are associated with worse outcomes in patients with nrLVO.

\section{INTRODUCTION}

Recent landmark randomized controlled clinical trials (RCTs) with successful recanalization (SR) rates ranging from $66 \%$ to $88 \%$ have provided unequivocal evidence that endovascular reperfusion with mechanical thrombectomy (MT) in patients with large vessel occlusion (LVO) is safe and improves functional outcomes. ${ }^{1-5}$ MT has become the new standard of care for acute ischemic stroke (AIS) due to LVO and health systems are reorganizing in order to implement this new therapy as quickly and as widely as possible. ${ }^{6}$

Current international recommendations on MT for AIS inadequately address blood pressure (BP) management before, during and after MT, given the lack of RCT data. ${ }^{78}$ In the absence of specific guidelines, endovascular centers usually target BP to remain below $180 / 105 \mathrm{mmHg}$ according to current American Heart Association (AHA) recommendations for BP management following intravenous thrombolysis (IVT) for AIS. ${ }^{9}$ Preliminary data have indicated that higher maximum values of systolic blood pressure (SBP) during the first 24 hours following MT are independently associated with worse functional outcomes, higher mortality, and a higher rate of hemorrhagic complications in patients with LVO. ${ }^{10} 11$

Theoretically, BP control may be beneficial in LVO patients with SR following MT, since they are at risk of reperfusion hemorrhage following effective clot removal. ${ }^{12-14}$ Our recent single-center study has provided preliminary data in support of this hypothesis, since it showed that moderate $\mathrm{BP}$ control in the first 24 hours following MT was related to lower odds of 3-month mortality compared with permissive hypertension in successfully recanalized LVO patients. ${ }^{11}$

Conversely, permissive hypertension may be beneficial in patients with non-recanalized LVO (nrLVO) by maintaining adequate brain perfusion pressure. ${ }^{12}$ Additionally, aggressive BP reduction in the first 24 hours of ictus has been associated with poor outcomes. ${ }^{15}$ Moreover, it may be argued that allowing the BP to spontaneously rise to optimize collateral blood flow may also assist in clearing emboli from distal vessels. ${ }^{16}$ However, the data evaluating the impact of permissive hypertension in the post-MT period on outcomes in nrLVO patients are scarce. In view of these considerations, we sought to evaluate the association of BP course in the first 24 hours following MT with safety and efficacy outcomes of patients with nrLVO.

\section{METHODS}

\section{Study population}

Data from consecutive LVO patients who underwent MT at a tertiary care stroke center from July 2013 to December 2016 were prospectively collected as previously described. ${ }^{17-19}$ At our 
comprehensive stroke center, the protocol-based practice is to perform MT for patients with CT angiography (CTA)-confirmed LVOs presenting within 6 hours of symptom onset. For the patients presenting 6-12 hours from symptom onset, additional imaging selection criteria are used such as Alberta Stroke Program Early CT Score (ASPECTS) $\geq 6$ on brain CT and/or good collaterals on CTA. LVO was diagnosed on pretreatment CTA using standard criteria. ${ }^{20}$ Brain CT head and CTA were performed on a 64-slice scanner. CT slice thickness was $1.25 \mathrm{~mm}$ with acquisitions in axial, sagittal, and coronal planes with 3D reformatting. A blinded neuroradiologistcalculated ASPECTS and CTA collateral scores as previously described. ${ }^{17}$ Collateral scores were reported in a dichotomized fashion (good vs poor collaterals) for anterior circulation LVO using a methodology that has been shown to predict clinical outcome. ${ }^{17}$

Recanalization at the end of the endovascular procedure was defined by modified Thrombolysis in Cerebral Infarction (mTICI) grades, ${ }^{21}$ which were obtained from the reports of endovascular specialists (LE, AA, DH). For the purpose of this study, successfully recanalized (mTICI grades $2 \mathrm{~b}$ or 3 ) LVO patients were excluded from the analyses and only nrLVO patients (mTICI grades $0,1,2 \mathrm{a}$ ) were further evaluated. At our center, AIS patients with emergent LVO are treated according to the AHA guidelines advocating IVT for all eligible patients and subsequent MT in cases with confirmed LVO by CTA. Some of the common reasons for not delivering IVT were delayed time window on presentation, pretreatment with oral anticoagulation therapy, and uncontrolled hypertension. In these situations, patients underwent direct MT without IVT pretreatment. Cerebral edema was determined to be present if both of the following criteria were met on two or more axial diffusion-weighted imaging (DWI) slices of the brain MRI which all patients underwent within 24-48 hours from symptom onset: (1) direct evidence of mass effect of affected gyri; or (2) indirect evidence based on new distortion of adjacent tissue, new midline shift, or new effacement of sulci or lateral ventricle. This two-by-two method was employed to reduce the chance of misclassifying infarct growth as swelling. ${ }^{22}$

\section{Baseline characteristics}

Stroke severity at hospital admission was documented using the National Institute of Health Stroke Scale (NIHSS) score by certified vascular neurologists. Baseline characteristics including demographics, vascular risk factors, admission NIHSS scores, admission ASPECTS, pretreatment with IVT, admission serum glucose, admission serum low density lipoprotein (LDL), admission systolic blood pressure (SBP) and diastolic blood pressure (DBP) levels were recorded as previously described. ${ }^{11} 2023$

\section{BP management post MT}

Hourly SBP and DBP recordings were obtained in all LVO patients during the first 24 hours following MT using oscillometric non-invasive BP monitoring devices as previously described. ${ }^{9}$ We documented minimum, mean, and maximum SBP and DBP levels for each individual patient during the BP monitoring period. Standard of care at our tertiary care center is to allow permissive hypertension in nrLVO patients post MT with BP goal of $<220 / 120 \mathrm{mmHg}$ for patients without pretreatment with IVT according to AHA recommendations for AIS management. ${ }^{24}$ For patients pretreated with IVT, permissive hypertension was set at $<180 / 105 \mathrm{mmHg}$ as advocated by AHA recommendations. ${ }^{24}$ Intravenous nicardipine was the first-line BP-lowering medication that we used for treating patients with BP levels exceeding the former prespecified cut-offs. Second-line antihypertensive agents were intravenous labetalol or intravenous enalapril. If nrLVO patients developed symptomatic intracranial hemorrhage (sICH) post MT, BP goals were modified according to the treating physician's preference $(<140 / 90 \mathrm{mmHg}$ or $<160 / 90 \mathrm{mmHg}$ ). Institutional Investigation Review Board approval for this study was granted based on the prospectively maintained Acute Ischemic Stroke Database. The Board waived the need for patient consent.

\section{Definition of outcomes}

sICH was defined as the presence of a parenchymal hematoma type 2 on brain CT and/or MRI gradient recall echo sequence accounting for deterioration with an increase in NIHSS score of $\geq 4$ points within 36 hours from treatment. ${ }^{25}$ Functional outcome was evaluated at 3 months using the modified Rankin Scale (mRS) scores by certified vascular neurologists. Functional status was evaluated in person either from a post hospital discharge clinic follow-up or from a hospital visit in all patients. Functional independence (FI) was defined as mRS scores of $0-2 .^{23}$ Endovascular specialists grading the degree of reperfusion at the end of MT and vascular neurologists assessing NIHSS and mRS scores were unaware of the purposes of the study and performed treatments and assessments as part of their clinical duties. The primary outcome included 3-month FI, while sICH and 3-month mortality represented secondary outcomes. Final infarct volume (FIV) was also calculated by the simplification of the ellipsoid rule $\mathrm{A} \times \mathrm{B} \times \mathrm{C} / 2$ on delayed (7-14 days) brain MRI using Fluid Averted Inversion Recovery (FLAIR) sequences. ${ }^{20}$ Delayed brain CT was used in a small number of patients with contraindications to brain MRI. ${ }^{20}$

\section{Statistical analyses}

Continuous variables are presented as mean \pm SD (normal distribution) and as median with interquartile range (skewed distribution). Categorical variables are presented as percentages with their corresponding 95\% CIs. Statistical comparisons for categorical variables between two or three groups were performed using a $\chi^{2}$ test, or in case of small expected frequencies, Fisher's exact test. Continuous variables were compared using the unpaired t-test, Mann-Whitney $U$ test, one-way analysis of variance or Kruskal-Wallis test as indicated. The correlation of BP measurements with FIV was evaluated using Spearman's correlation coefficient (r). Univariable and multivariable logistic regression models were used to evaluate associations between BP measurements during the first 24 hours following MT (mean, minimum, and maximum SBP and DBP post MT) with 3-month FI, 3-month mortality and sICH before and after adjustment for the following potential confounders: age, gender, race, vascular risk factors (hypertension, diabetes mellitus, hypercholesterolemia, atrial fibrillation, coronary artery disease, congestive heart failure and current smoking), admission SBP and DBP levels, admission stroke severity, admission serum glucose and LDL levels, pretreatment with IVT, baseline ASPECTS, onset to groin puncture time, type of anesthesia (general anesthesia vs conscious sedation), brain edema, and good collaterals. Associations are presented as OR with corresponding 95\% CI. In the initial univariable analyses a $\mathrm{P}$ value $<0.1$ was set as the threshold for inclusion in the multivariable models. Statistical significance was achieved for $\mathrm{P}<0.05$ in the final multivariable analyses. The Statistical Package for Social Science (SPSS Version 22.0 for Windows) was used for statistical analyses.

\section{RESULTS}

Our study population consisted of 88 nrLVO patients (mean age $62 \pm 15$ years, $48 \%$ median NIHSS score 16 points (IQR 12-21), 
Table 1 Baseline characteristics of the study population

\begin{tabular}{|c|c|}
\hline Variable & $\mathrm{n}=88$ \\
\hline Mean (SD) age, years & $62(15)$ \\
\hline Male gender, n (\%) & $42(48)$ \\
\hline Caucasians, n (\%) & $36(41)$ \\
\hline Black race, n (\%) & $52(59)$ \\
\hline Hypertension, n (\%) & $69(78)$ \\
\hline Diabetes mellitus, n (\%) & $28(32)$ \\
\hline Hypercholesterolemia, n (\%) & $32(37)$ \\
\hline Atrial fibrillation, n (\%) & $27(31)$ \\
\hline Smoking, n (\%) & $23(26)$ \\
\hline Coronary artery disease, $\mathrm{n}(\%)$ & $16(18)$ \\
\hline Congestive heart failure, $\mathrm{n}(\%)$ & $15(17)$ \\
\hline Median baseline NIHSS score, points (IQR) & $16(12-21)$ \\
\hline Pretreatment with intravenous thrombolysis, n (\%) & $56(64)$ \\
\hline Mean (SD) admission systolic blood pressure, $\mathrm{mmHg}$ & $157(32)$ \\
\hline Mean (SD) admission diastolic blood pressure, $\mathrm{mmHg}$ & $89(20)$ \\
\hline Mean (SD) systolic blood pressure post $\mathrm{MT}^{*}, \mathrm{mmHg}$ & $141(15)$ \\
\hline Mean (SD) diastolic blood pressure post $\mathrm{MT}^{*}, \mathrm{mmHg}$ & $72(12)$ \\
\hline Minimum (SD) systolic blood pressure post $\mathrm{MT}^{*}, \mathrm{mmHg}$ & $110(22)$ \\
\hline Minimum (SD) diastolic blood pressure post $\mathrm{MT}^{*}, \mathrm{mmHg}$ & $55(12)$ \\
\hline Maximum (SD) systolic blood pressure post $\mathrm{MT}^{*}, \mathrm{mmHg}$ & $174(23)$ \\
\hline Maximum diastolic blood pressure post $\mathrm{MT}^{*}, \mathrm{mmHg}_{\text {(SD) }}$ & $94(20)$ \\
\hline Mean (SD) admission serum glucose, mg/dL & $153(82)$ \\
\hline Mean (SD) admission low density lipoprotein, mg/dL & $99(40)$ \\
\hline General anesthesia, n (\%) & $33(38 \%)$ \\
\hline Good collaterals, n (\%) & $31(52 \%) \dagger$ \\
\hline Median (IQR) ASPECTS, points & $9(8-10)$ \\
\hline Median (IQR) onset to tPA bolus time, min & $130(105-172)$ \\
\hline Median (IQR) onset to arterial puncture time, min & $226(171-290)$ \\
\hline
\end{tabular}

median onset to groin puncture time $226 \mathrm{~min}$ (IQR 171-290)). The baseline characteristics of our study population are shown in table 1. The location of LVO was the following: 31 in the M1 middle cerebral artery (MCA; 35\%), 16 in the intracranial internal carotid artery (ICA; 18\%), 12 in the posterior circulation (14\%), 10 in M2 MCA (11\%). The remaining 19 patients had tandem occlusions (22\%). A total of 33 patients underwent MT under general anesthesia (38\%), while the remaining 55 patients $(62 \%)$ received conscious sedation.

In our cohort, a combination of distal aspiration and stent-retriever was used as the most common technique in 47 cases (53\%). The second most commonly employed technique was the ADAPT (A Direct Aspiration First Pass Technique), and this was used in 22 cases $(25 \%)$. Stent-retrievers without distal aspiration were used in 15 cases (17\%). The remaining cases were mostly cervical or intracranial carotid occlusions in which acute angioplasty and/or stenting was employed. Systemic thrombolysis prior to MT was administered in 56 patients (64\%). The rate of sICH was $9 \%$. Cerebral edema occurred in 32 patients (37\%). A total of $27 \%$ of patients achieved FI at 3 months, while the 3 -month mortality rate was $37 \%$.

The univariable associations of maximal SBP and DBP levels post MT with primary (FI) and secondary (sICH and 3 month mortality) outcomes are summarized in table 2. Patients with FI had lower maximal SBP $(160 \pm 19 \mathrm{mmHg}$ vs $179 \pm 23 \mathrm{mmHg}$; $\mathrm{P}=0.001$ ), while maximal DBP did not differ between the two groups $(88 \pm 14 \mathrm{mmHg}$ vs $96 \pm 22 \mathrm{mmHg} ; \mathrm{P}=0.157)$. Maximal SBP levels $(183 \pm 20 \mathrm{mmHg}$ vs $169 \pm 23 \mathrm{mmHg} ; \mathrm{P}=0.008)$ and DBP levels $(105 \pm 20 \mathrm{mmHg}$ vs $89 \pm 18 \mathrm{mmHg} ; \mathrm{P}=0.001)$ post MT were higher in patients who died at 3 months, while no difference was noted in maximal SBP $(183 \pm 31 \mathrm{mmHg}$ vs $173 \pm 22 \mathrm{mmHg}$; $\mathrm{P}=0.279)$ and $\mathrm{DBP}(97 \pm 25 \mathrm{mmHg}$ vs $94 \pm 20 \mathrm{mmHg} ; \mathrm{P}=0.692)$ levels in patients with and without sICH. Increasing maximal SBP measurements strongly correlated to larger FIV (Spearman's r: 0.534; $\mathrm{P}<0.001)$. There was no correlation $(\mathrm{P}>0.080)$ between any of the remaining BP measurements and FIV.

Table 2 also depicts the associations of minimum SBP and DBP levels post MT with primary and secondary outcomes. Patients with FI had higher minimum SBP levels $(119 \pm 12 \mathrm{mmHg}$ vs $108 \pm 25 \mathrm{mmHg} ; \mathrm{P}=0.009$ ), while minimal SBP values were lower in patients who died at 3 months $(102 \pm 28 \mathrm{mmHg}$ vs

Table 2 Maximum and minimum systolic blood pressure (SBP) and diastolic blood pressure (DBP) levels during the first 24 hours following the end of mechanical thrombectomy (MT) in relation to primary (3-month functional independence) and secondary (symptomatic intracranial hemorrhage and 3-month mortality) outcomes

\begin{tabular}{|c|c|c|c|c|c|c|}
\hline \multirow{2}{*}{$\begin{array}{l}\text { Outcome } \\
\text { Primary }\end{array}$} & \multicolumn{2}{|c|}{$\begin{array}{l}\text { Maximum SBP post MT } \\
(m e a n \pm S D), m m H g\end{array}$} & \multirow[t]{2}{*}{$P$ value } & \multicolumn{2}{|c|}{$\begin{array}{l}\text { Maximum DBP post MT } \\
(m e a n \pm S D), m m H g\end{array}$} & \multirow[t]{2}{*}{$P$ value } \\
\hline & Yes & No & & Yes & No & \\
\hline Secondary & Yes & No & & Yes & No & \\
\hline Symptomatic intracranial hemorrhage & $183 \pm 31$ & $173 \pm 22$ & 0.279 & $97 \pm 25$ & $94 \pm 20$ & 0.692 \\
\hline Three-month mortality & $183 \pm 20$ & $169 \pm 23$ & 0.008 & $105 \pm 20$ & $89 \pm 18$ & 0.001 \\
\hline Primary & Yes & No & & Yes & No & \\
\hline Three-month functional independence* & $119 \pm 12$ & $108 \pm 25$ & 0.008 & $54 \pm 11$ & $55 \pm 12$ & 0.757 \\
\hline Secondary & Yes & No & & Yes & No & \\
\hline Symptomatic intracranial hemorrhage & $105 \pm 18$ & $111 \pm 22$ & 0.430 & $51 \pm 9$ & $55 \pm 12$ & 0.384 \\
\hline
\end{tabular}


Table 3 Mean systolic blood pressure (SBP) and diastolic blood pressure (DBP) levels during the first 24 hours following the end of mechanical thrombectomy (MT) in relation to primary (3-month functional independence) and secondary (symptomatic intracranial hemorrhage, and 3-month mortality) outcomes

\begin{tabular}{|c|c|c|c|c|c|c|}
\hline \multirow{2}{*}{$\frac{\text { Outcome }}{\text { Primary }}$} & \multicolumn{2}{|c|}{$\begin{array}{l}\text { Mean SBP post MT } \\
(m e a n \pm S D), m m H g\end{array}$} & \multirow[t]{2}{*}{$P$ value } & \multicolumn{2}{|c|}{$\begin{array}{l}\text { Mean DBP post } \\
\text { MT (mean } \pm S D) \text {, } \\
\text { mmHg }\end{array}$} & \multirow[t]{2}{*}{$P$ value } \\
\hline & Yes & No & & Yes & No & \\
\hline $\begin{array}{l}\text { Three-month } \\
\text { functional } \\
\text { independence* }\end{array}$ & $140 \pm 13$ & $141 \pm 17$ & 0.798 & $71 \pm 11$ & $72 \pm 12$ & 0.579 \\
\hline Secondary & Yes & No & & Yes & No & \\
\hline $\begin{array}{l}\text { Symptomatic } \\
\text { intracranial } \\
\text { hemorrhage }\end{array}$ & $139 \pm 18$ & $141 \pm 15$ & 0.698 & $74 \pm 12$ & $72 \pm 12$ & 0.710 \\
\hline $\begin{array}{l}\text { Three-month } \\
\text { mortality }\end{array}$ & $142 \pm 17$ & $140 \pm 15$ & 0.568 & $74 \pm 14$ & $71 \pm 10$ & 0.221 \\
\hline
\end{tabular}

${ }^{*}$ Three-month functional independence: mRS scores of $0-2$.

$115 \pm 16 \mathrm{mmHg} ; \mathrm{P}=0.007)$. No other association was detected between minimal SBP and DBP values post MT with the outcomes of interest. We also failed to document any association between mean SBP and DBP levels post MT and primary or secondary outcomes (table 3). Moreover, all post MT BP measurements did not differ $(\mathrm{P}>0.2)$ between patients with good and bad collateral status.

Table 4 shows the univariable and multivariable associations of BP measurements post MT and other baseline characteristics with 3-month FI. In the initial univariable analyses the following variables were related $(\mathrm{P}<0.1)$ to $\mathrm{FI}$ : admission $\mathrm{SBP}$, admission NIHSS score, maximum SBP post MT and minimum SBP post MT. In the final multivariable models both minimum and maximum SBP were independently associated with FI. More specifically, a $10 \mathrm{mmHg}$ increment in maximum SBP reduced the odds of FI (OR $0.55,95 \%$ CI 0.39 to $0.79 ; \mathrm{P}=0.001$ ), while a $10 \mathrm{mmHg}$ increment in minimum SBP increased the likelihood of FI (OR 1.64, 95\% CI 1.04 to $2.60 ; \mathrm{P}=0.033$ ).

Table 5 summarizes the univariable and multivariable associations of BP measurements post MT and other baseline characteristics with 3 -month mortality. In the initial univariable analyses the following variables were related $(\mathrm{P}<0.1)$ to mortality: admission SBP, admission NIHSS score, general anesthesia (vs conscious sedation), maximum SBP post MT, minimum SBP post MT, and maximum DBP post MT. In the final multivariable models both minimum SBP and maximum DBP were independently associated with mortality. More specifically, a $10 \mathrm{mmHg}$ increment in maximum DBP increased the odds of mortality (OR 1.62; $95 \%$ CI 1.10 to $2.38 ; \mathrm{P}=0.014$ ), while a $10 \mathrm{mmHg}$ increment in minimum SBP decreased the likelihood of mortality (OR 0.68 , $95 \%$ CI 0.49 to $0.95 ; \mathrm{P}=0.022$ ).

We also performed sensitivity analyses (table 6) evaluating the association of post-MT BP measurements with outcomes in the subgroup of nrLVO patients without IVT pretreatment $(n=32)$. Our sensitivity analyses reproduced the significant associations that were documented in the total study sample. Patients with 3-month FI had lower maximal SBP $(160 \pm 19 \mathrm{mmHg}$ vs $177 \pm 17 \mathrm{mmHg} ; \mathrm{P}=0.040)$, while maximal SBP levels $(181 \pm 8 \mathrm{mmHg}$ vs $167 \pm 22 \mathrm{mmHg} ; \mathrm{P}=0.025)$ post MT were higher in patients who died at 3 months. In addition, lower minimal SBP levels were also related to 3-month mortality $(101 \pm 18 \mathrm{mmHg}$ vs $115 \pm 18 \mathrm{mmHg} ; \mathrm{P}=0.038)$.
Table 4 Univariable and multivariable logistic regression analyses depicting the associations of blood pressure measurements and other baseline characteristics with 3-month functional independence ( $\mathrm{mRS}$ score of $0-2$ )

\begin{tabular}{|c|c|c|c|c|}
\hline \multirow[b]{2}{*}{ Variable } & \multicolumn{2}{|c|}{$\begin{array}{l}\text { Univariable logistic regression } \\
\text { analysis }\end{array}$} & \multicolumn{2}{|c|}{$\begin{array}{l}\text { Multivariable logistic } \\
\text { regression analysis* }\end{array}$} \\
\hline & OR $(95 \% \mathrm{Cl})$ & P value* & OR $(95 \% \mathrm{Cl})$ & $P$ value \\
\hline $\begin{array}{l}\text { Age (per } 10 \text { year } \\
\text { increase) }\end{array}$ & $0.82(0.59$ to 1.14$)$ & 0.239 & & \\
\hline Male gender & $0.86(0.32$ to 2.30$)$ & 0.767 & & \\
\hline Black race & 0.88 (0.33 to 2.36$)$ & 0.803 & & \\
\hline $\begin{array}{l}\text { NIHSS score at } \\
\text { admission (per } 1 \text { point } \\
\text { increase) }\end{array}$ & 0.85 (0.77 to 0.94$)$ & 0.001 & 0.86 (0.76 to 0.97 ) & 0.017 \\
\hline
\end{tabular}

\begin{tabular}{|c|c|c|c|c|}
\hline $\begin{array}{l}\text { ASPECTS at baseline } \\
\text { (per } 1 \text { point increase) }\end{array}$ & 1.14 (0.78 to 1.67$)$ & 0.486 & & \\
\hline Good collaterals & 1.01 (0.29 to 3.52$)$ & 0.991 & & \\
\hline Hypertension & 0.96 (0.30 to 3.10$)$ & 0.947 & & \\
\hline Diabetes mellitus & 0.80 (0.30 to 2.17$)$ & 0.665 & & \\
\hline Hyperlipidemia & 0.85 (0.34 to 2.11$)$ & 0.721 & & \\
\hline Atrial fibrillation & 0.79 (0.27 to 2.34$)$ & 0.670 & & \\
\hline $\begin{array}{l}\text { Coronary artery } \\
\text { disease }\end{array}$ & $0.97(0.27$ to 3.44$)$ & 0.962 & & \\
\hline $\begin{array}{l}\text { Congestive heart } \\
\text { failure }\end{array}$ & 2.14 (0.60 to 7.65$)$ & 0.240 & & \\
\hline Smoking & $0.67(0.21$ to 2.10$)$ & 0.491 & & \\
\hline $\begin{array}{l}\text { Intravenous } \\
\text { thrombolysis }\end{array}$ & $1.96(0.67$ to 5.72$)$ & 0.218 & & \\
\hline $\begin{array}{l}\text { Onset to arterial } \\
\text { puncture time } \\
\text { (per } 10 \text { min increase) }\end{array}$ & 0.98 (0.95 to 1.02$)$ & 0.311 & & \\
\hline $\begin{array}{l}\text { General anesthesia (vs } \\
\text { conscious sedation) }\end{array}$ & 0.59 (0.20 to 1.72$)$ & 0.331 & & \\
\hline $\begin{array}{l}\text { Serum glucose at } \\
\text { admission (per } 10 \mathrm{mg} / \mathrm{dL} \\
\text { increase) }\end{array}$ & 1.00 (0.95 to 1.06$)$ & 0.895 & & \\
\hline $\begin{array}{l}\text { Serum LDL (per } 10 \mathrm{mg} / \\
\mathrm{dL} \text { increase) }\end{array}$ & 1.02 (0.90 to 1.15$)$ & 0.810 & & \\
\hline $\begin{array}{l}\text { SBP at admission (per } \\
10 \mathrm{mmHg} \text { increase) }\end{array}$ & $0.83(0.70$ to 1.00$)$ & 0.044 & 0.89 (0.69 to 1.14$)$ & 0.357 \\
\hline $\begin{array}{l}\text { Mean SBP post MT } \\
\text { (per } 10 \mathrm{mmHg} \\
\text { increase) } \dagger\end{array}$ & $0.96(0.70$ to 1.31$)$ & 0.795 & & \\
\hline $\begin{array}{l}\text { Minimum SBP post MT } \\
\text { (per } 10 \mathrm{mmHg} \\
\text { increase) } \dagger\end{array}$ & 1.31 (1.00 to 1.72$)$ & 0.048 & 1.64 (1.04 to 2.60$)$ & 0.033 \\
\hline $\begin{array}{l}\text { Maximum SBP post } \\
\text { MT per } 10 \mathrm{mmHg} \\
\text { increase) } \dagger\end{array}$ & 0.67 (0.51 to 0.87$)$ & 0.003 & 0.55 (0.39 to 0.79$)$ & 0.001 \\
\hline
\end{tabular}

$\begin{array}{lll}\begin{array}{l}\text { DBP at admission } \\ \text { (per } 10 \mathrm{mmHg} \\ \text { increase) }\end{array} & 0.87(0.67 \text { to } 1.13) & 0.299 \\ \begin{array}{l}\text { Mean DBP post MT } \\ \text { (per } 10 \mathrm{mmHg}\end{array} & 0.89(0.58 \text { to } 1.35) & 0.574 \\ \text { increase) } \dagger\end{array}$

${ }^{*}$ Cut-off of $\mathrm{P}<0.1$ was used for selection of candidate variables for inclusion in multivariable logistic regression models.

tDuring the first 24 hours following the end of mechanical thrombectomy.

ASPECTS, Alberta Stroke Program Early CT score; DBP, diastolic blood pressure; LDL, low density lipoprotein; MT, mechanical thrombectomy; NIHSS, National Institutes of Health Stroke Scale; SBP, systolic blood pressure. 
Table 5 Univariable and multivariable logistic regression analyses depicting the associations of blood pressure measurements and other baseline characteristics with 3-month mortality

\begin{tabular}{|c|c|c|c|c|}
\hline \multirow[b]{2}{*}{ Variable } & \multicolumn{2}{|c|}{$\begin{array}{l}\text { Univariable logistic regression } \\
\text { analysis }\end{array}$} & \multicolumn{2}{|c|}{$\begin{array}{l}\text { Multivariable logistic regression } \\
\text { analysis* }\end{array}$} \\
\hline & OR $(95 \% \mathrm{Cl})$ & $P$ value* & OR $(95 \% \mathrm{Cl})$ & $P$ value \\
\hline Age (per 10 year increase) & 1.12 (0.83 to 1.50$)$ & 0.460 & & \\
\hline Male gender & 0.94 (0.39 to 2.27$)$ & 0.886 & & \\
\hline Black race & $1.18(0.48$ to 2.90$)$ & 0.726 & & \\
\hline $\begin{array}{l}\text { NIHSS score at admission } \\
\text { (per } 1 \text { point increase) }\end{array}$ & 1.13 (1.04 to 1.22$)$ & 0.003 & 1.11 (1.00 to 1.23$)$ & 0.049 \\
\hline $\begin{array}{l}\text { ASPECTS at baseline (per } 1 \\
\text { point increase) }\end{array}$ & 0.87 (0.65 to 1.17 ) & 0.362 & & \\
\hline Good collaterals & 0.71 (0.25 to 2.04$)$ & 0.523 & & \\
\hline Hypertension & 1.82 (0.59 to 5.66$)$ & 0.301 & & \\
\hline Diabetes mellitus & 1.63 (0.68 to 3.91$)$ & 0.276 & & \\
\hline Hyperlipidemia & 0.68 (0.29 to 1.59$)$ & 0.376 & & \\
\hline Atrial fibrillation & $1.43(0.56$ to 3.69$)$ & 0.459 & & \\
\hline Coronary artery disease & $1.06(0.34$ to 3.25$)$ & 0.962 & & \\
\hline Congestive heart failure & $0.60(0.17$ to 2.09$)$ & 0.423 & & \\
\hline Smoking & $1.50(0.57$ to 3.99$)$ & 0.415 & & \\
\hline Intravenous thrombolysis & 0.75 (0.30 to 1.86$)$ & 0.537 & & \\
\hline $\begin{array}{l}\text { Onset to arterial puncture } \\
\text { time } \\
\text { (per } 10 \mathrm{~min} \text { increase) }\end{array}$ & 1.00 (0.98 to 1.03$)$ & 0.975 & & \\
\hline $\begin{array}{l}\text { General anesthesia (vs } \\
\text { conscious sedation) }\end{array}$ & 2.88 (1.15 to 7.22$)$ & 0.024 & 2.73 (0.83 to 8.92 ) & 0.097 \\
\hline $\begin{array}{l}\text { Serum glucose at } \\
\text { admission (per } 10 \mathrm{mg} / \mathrm{dL} \\
\text { increase) }\end{array}$ & 1.01 (0.96 to 1.06$)$ & 0.810 & & \\
\hline $\begin{array}{l}\text { Serum LDL (per } 10 \mathrm{mg} / \mathrm{dL} \\
\text { increase) }\end{array}$ & 0.94 (0.83 to 1.06$)$ & 0.285 & & \\
\hline $\begin{array}{l}\text { SBP at admission (per } \\
10 \mathrm{mmHg} \text { increase) }\end{array}$ & 1.19 (1.03 to 1.38$)$ & 0.019 & 1.21 (0.98 to 1.48$)$ & 0.072 \\
\hline $\begin{array}{l}\text { Mean SBP post MT (per } \\
10 \mathrm{mmHg} \text { increase) } \dagger\end{array}$ & 1.09 (0.81 to 1.46$)$ & 0.564 & & \\
\hline $\begin{array}{l}\text { Minimum SBP post MT } \\
\text { (per } 10 \mathrm{mmHg} \text { increase) } \dagger\end{array}$ & 0.72 (0.56 to 0.94$)$ & 0.015 & 0.68 (0.49 to 0.95$)$ & 0.022 \\
\hline $\begin{array}{l}\text { Maximum SBP post MT } \\
\text { (per } 10 \mathrm{mmHg} \text { increase) } \dagger\end{array}$ & 1.25 (1.01 to 1.55$)$ & 0.042 & 1.12 (0.83 to 1.50$)$ & 0.464 \\
\hline $\begin{array}{l}\text { DBP at admission (per } \\
10 \mathrm{mmHg} \text { increase) }\end{array}$ & $1.17(0.93$ to 1.47$)$ & 0.177 & & \\
\hline $\begin{array}{l}\text { Mean DBP post MT (per } \\
10 \mathrm{mmHg} \text { increase) } t\end{array}$ & 1.28 (0.86 to 1.88$)$ & 0.220 & & \\
\hline $\begin{array}{l}\text { Minimum DBP post MT } \\
\text { (per } 10 \mathrm{mmHg} \text { increase) } \dagger\end{array}$ & $0.96(0.65$ to 1.41$)$ & 0.823 & & \\
\hline $\begin{array}{l}\text { Maximum DBP post MT } \\
\text { (per } 10 \mathrm{mmHg} \text { increase) } \dagger\end{array}$ & 1.55 (1.14 to 2.10$)$ & 0.005 & 1.62 (1.10 to 2.38 ) & 0.014 \\
\hline Brain edema & 1.79 (0.72 to 4.46$)$ & 0.209 & & \\
\hline $\begin{array}{l}{ }^{*} \text { Cut-off of } \mathrm{P}<0.1 \text { was used } \\
\text { regression models. } \\
\text { †During the first } 24 \text { hours fo } \\
\text { ASPECTS, Alberta Stroke Pro } \\
\text { lipoprotein; MT, mechanical } \\
\text { blood pressure. }\end{array}$ & $\begin{array}{l}\text { for selection of candi } \\
\text { Ilowing the end of me } \\
\text { gram Early CT score; } \\
\text { thrombectomy; NIHSS }\end{array}$ & $\begin{array}{l}\text { ariables for } \\
\text { ical thrombe } \\
\text { liastolic bloc } \\
\text { onal Institu }\end{array}$ & $\begin{array}{l}\text { nclusion in multivariable } \\
\text { tomy. } \\
\text { d pressure; LDL, low den } \\
\text { es of Health Stroke Scale }\end{array}$ & gistic \\
\hline
\end{tabular}

\section{DISCUSSION}

Our study demonstrates that wide BP excursions from the mean during the first 24 hours post MT are associated with worse outcomes in patients with nrLVO. This association was independent of demographics, vascular risk factors, baseline stroke severity, onset to groin puncture time, admission BP, serum glucose and LDL levels, early hypodensity on brain CT quantified by ASPECTS, type of anesthesia, collateral status, and early brain edema.

Successful reperfusion rates post MT have improved from $40-50 \%$ with first-generation devices to $70-90 \%$ with third-generation devices like stent-retrievers or aspiration catheters during the past 15 years. $^{26} 27$ Considering the fact that $10-30 \%$ of LVO patients still remain non-recanalized post MT carrying a dismal prognosis, it is important to identify other modifiable variables that might improve functional outcomes in this subgroup. Effective post-procedural BP management may be one of these factors. Theoretically, permissive hypertension may be beneficial in patients with nrLVO to maintain brain perfusion pressure. In our cohort of nrLVO patients, we documented that increasing maximum SBP and DBP levels during the first 24 hours following MT were associated with a higher likelihood of 3-month mortality and lower odds of 3-month FI. This finding is partly in line with a recent retrospective observational study that also reported an independent relationship between peak SBP levels during the first 24 hours following MT and worse functional outcomes at 3 months in a broader patient population (both recanalized and non-recanalized LVO patients). ${ }^{10}$ On the other hand, minimum post-MT BP levels did not affect outcomes in the study by Mistry et al ${ }^{10}$ Nevertheless, there are important methodological considerations when comparing the two studies. First, the study population of patients with non-recanalized emergent LVO in our study $(\mathrm{n}=88)$ is almost double that in the study by Mistry et al $(n=45) .{ }^{10}$ Second, in the earlier study by Mistry and colleagues only 34 nrLVO patients had 90-day mRS evaluations available. ${ }^{10}$ Therefore, their analysis was underpowered to reveal independent associations between post-MT BP measurements and 90-day functional outcomes. On the other hand, our study evaluated the association of post-MT BP levels with safety and efficacy outcomes using comprehensive univariable and multivariable logistic regression models.

The association of elevated maximum BP post MT with adverse functional outcomes cannot be attributed to the potential impairment of collateral circulation with extremely elevated BP levels in patients with LVO, since patients with good and bad collaterals in our cohort did not differ in any BP parameter post MT. ${ }^{28}$ The association of increasing BP levels with increasing final infarct volume seen in the present study, detected both by our group ${ }^{20}$ and other investigators in previous studies, ${ }^{29}$ may account for the detrimental effect of higher maximum SBP and DBP post MT on functional outcomes. Alternative explanations may suggest that patients with exceptionally high BP are unhealthier due to coexisting comorbidities (diabetes mellitus, renal failure) or that acutely raised $\mathrm{BP}$ levels are a marker of extensive cerebral ischemia and early brain swelling. However, it is noteworthy that brain edema was included as a potential confounder in all analyses without modifying any of the reported associations.

In addition, we detected that lower minimum SBP levels post MT correlated to higher odds of mortality and functional dependence at 3 months. A U-shaped association between acute $\mathrm{BP}$ values and outcomes in AIS has been firmly established by multiple observational studies, indicating that extremely low BP levels during the first hours of acute cerebral ischemia are equally as harmful as markedly elevated BP values. ${ }^{29-31} \mathrm{~A}$ similar U-shaped relationship between baseline SBP and functional outcome in LVO patients treated with MT has recently been reported by the MR CLEAN (Multicenter Randomized Clinical Trial of Endovascular Treatment of Acute Ischemic Stroke in the Netherlands) investigators. ${ }^{32}$ The detrimental effect of extremely low BP values following MT in patients with nrLVO may be attributed to impaired cerebral perfusion due to autoregulatory failure leading to infarct expansion and further neurological deterioration. ${ }^{14} 33$

Nevertheless, the fact that maximum and minimum and not mean BP levels were associated with adverse outcomes indirectly 
Table 6 Maximum and minimum systolic blood pressure (SBP) and diastolic blood pressure (DBP) levels during the first 24 hours following the end of mechanical thrombectomy (MT) in relation to primary (3-month functional independence) and secondary (symptomatic intracranial hemorrhage and 3-month mortality) outcomes in the subgroup of patients with emergent large vessel occlusion without intravenous thrombolysis pretreatment $(n=32)$

\begin{tabular}{|c|c|c|c|c|c|c|}
\hline \multirow{2}{*}{$\begin{array}{l}\text { Outcome } \\
\text { Primary }\end{array}$} & \multicolumn{2}{|c|}{$\begin{array}{l}\text { Maximum SBP post MT } \\
(\text { mean } \pm S D), m m H g\end{array}$} & \multirow[t]{2}{*}{$P$ value } & \multicolumn{2}{|c|}{$\begin{array}{l}\text { Maximum DBP post MT } \\
(m e a n \pm S D), m m H g\end{array}$} & \multirow[t]{2}{*}{$P$ value } \\
\hline & Yes & No & & Yes & No & \\
\hline Three-month functional independence* & $160 \pm 19$ & $177 \pm 17$ & 0.040 & $93 \pm 11$ & $94 \pm 20$ & 0.923 \\
\hline Secondary & Yes & No & & Yes & No & \\
\hline Symptomatic intracranial hemorrhage & $169 \pm 57$ & $173 \pm 15$ & 0.925 & $99 \pm 22$ & $94 \pm 19$ & 0.638 \\
\hline Three-month mortality & $181 \pm 8$ & $167 \pm 22$ & 0.025 & $97 \pm 14$ & $92 \pm 22$ & 0.500 \\
\hline Primary & Yes & No & & Yes & No & \\
\hline Three-month functional independence* & $121 \pm 15$ & $107 \pm 19$ & 0.104 & $57 \pm 11$ & $54 \pm 11$ & 0.528 \\
\hline Secondary & Yes & No & & Yes & No & \\
\hline Symptomatic intracranial hemorrhage & $98 \pm 8$ & $110 \pm 20$ & 0.274 & $53 \pm 5$ & $55 \pm 12$ & 0.761 \\
\hline
\end{tabular}

${ }^{*}$ Three months functional independence: mRS scores of $0-2$.

supports the potential detrimental effect of extreme BP fluctuations during the immediate post-procedural period. The findings of our study are corroborated by a recent retrospective study which demonstrated worse clinical outcomes in non-recanalized AIS patients with the highest and the lowest BP values following reperfusion with IVT or endovascular procedures. ${ }^{33}$ Additional well-designed multicenter studies are required to independently validate our initial observations and to determine the cut-off values above and below which BP should not fluctuate during the first critical hours following MT.

It is plausible to hypothesize that, among patients with nrLVO, those with viable penumbra are most likely to benefit from permissive hypertension. Although there is no easy way to quantify penumbra, high ASPECTS and good collaterals can be used as surrogates for viable hypoperfused cerebral tissue. In the present study, we included in our analyses both ASPECTS and collateral score as potential confounders that may moderate the association of BP measurements with 3-month FI (mRS score of $0-2$ ) and 3-month mortality (tables 4 and 5). However, we failed to detect any significant interaction. Nevertheless, this lack of association may be attributed to a type II error due to the limited sample size $(n=88)$. Future multicenter larger studies should evaluate the potential beneficial effect of permissive hypertension following MT in the subgroup of patients with emergent LVO with adequate collaterals and high ASPECTS.

It is also possible that permissive hypertension may have resulted in small improvements in hand or language functions in nrLVO patients. However, these improvements could not be quantified by the mRS score, which is a course outcome. Unfortunately, the activities of daily living at 3 months were not prospectively evaluated in this dataset. We plan to implement Barthel Index as a standard outcome measure of activities of daily living at 3 months in our future studies. Furthermore, we failed to assess volume status, a potentially essential variable for patients with pressure dependent examination that may benefit the most with permissive hypertension. Nevertheless, it should be acknowledged that the common practice in our center is to maintain euvolemia using fluid administration.

Several other limitations of the present report need to be addressed. First, the modest sample size and retrospective analysis of prospectively collected data are important methodological shortcomings. Second, our methods included primary and secondary outcomes lacking central adjudication. Third, we did not collect data on fluctuation of BP levels during MT and BP variability post MT and could not evaluate their impact on different outcomes. Fourth, the limited sample size prevented us from differentiating between mTICI 0,1 and 2 a recanalization grades when investigating the impact of BP levels post MT on outcomes. We realize that this is an important limitation, however we feel that stratifying the present cohort according to different non-recanalized grades (mTICI 0,1 and 2a) will further significantly decrease the sample size in each group. This would make it difficult to draw any meaningful results/conclusions from the present study because of type II error. Future studies with a larger number of patients should stratify these groups. Fifth, patients with nrLVO pretreated with IVT had different post-MT BP goals $(<180 / 105 \mathrm{mmHg})$ from patients treated with direct MT $(<220 / 120 \mathrm{mmHg})$. Consequently, it would be important to differentiate these two groups in future larger studies, although it is important to note that IVT pretreatment was included as one of the potential confounders in our analyses and did not moderate the association of BP parameters with early functional outcomes and mortality. Sixth, follow-up vascular imaging after the termination of MT is not common practice at our center unless there is unexpected clinical worsening. Thus, we were unable to record the rates of spontaneous subsequent recanalization in the present dataset. Finally, the observational study design did not allow us to establish a cause-effect relationship between BP levels and outcomes in patients with nrLVO treated with MT. The strong correlation that we identified between increasing maximal SBP measurements and more extensive infarct volumes indicates that excessively high BP levels post MT may worsen functional outcome by increasing FIV.

In conclusion, our study demonstrates that nrLVO patients who do poorly are more likely to have had excursions of $\mathrm{BP}$ from the mean in the first 24 hours following MT. In the absence of RCT data, the majority of endovascular centers usually allow permissive hypertension for patients with nrLVO. Our preliminary findings indicate that extreme BP variations during the first 24 hours following MT are likely to be harmful and should be avoided. Additional well-designed multicenter 
studies are required to independently validate our initial observations and determine the actual cut-offs above and below which BP should not fluctuate during the first critical hours following MT. Future research is also necessary to identify the subgroup among nrLVO patients who are most likely to benefit from permissive hypertension (eg, patients with good collaterals and high ASPECTS).

Contributors NG: Study concept and design, acquisition of data, analysis and interpretation, critical revision of the manuscript for important intellectual content. GT: Analysis and interpretation, critical revision of the manuscript for important intellectual content. AP: Acquisition of data, critical revision of the manuscript for important intellectual content. KD: Acquisition of data, critical revision of the manuscript for important intellectual content. DA: Acquisition of data, critical revision of the manuscript for important intellectual content. JJC: Critical revision of the manuscript for important intellectual content. BK: Acquisition of data, critical revision of the manuscript for important intellectual content. CN: Acquisition of data, critical revision of the manuscript for important intellectual content. DH: Acquisition of data, critical revision of the manuscript for important intellectual content. KA: Critical revision of the manuscript for important intellectual content. AVA: Critical revision of the manuscript for important intellectual content. ASA: Acquisition of data, critical revision of the manuscript for important intellectual content. LE: Study concept and design, study supervision, critical revision of the manuscript for important intellectual content.

Competing interests DH: consultant for Codman Neurovascular, Medtronic, MicroVention, Penumbra, Sequent, and Stryker; ASA: consultant for Codman, Medtronic, Microvention, Penumbra, Sequent, Siemens, Stryker and has received research support from Sequent and Siemens; LE: consultant for Codman Neurovascular, Medtronic, MicroVention, Penumbra, Sequent, and Stryker.

Ethics approval University of Tennessee Health Sciences Center Acute Ischemic Stroke Database (10-01003-XP).

Provenance and peer review Not commissioned; externally peer reviewed.

(c) Article author(s) (or their employer(s) unless otherwise stated in the text of the article) 2018. All rights reserved. No commercial use is permitted unless otherwise expressly granted.

\section{REFERENCES}

1 Berkhemer $\mathrm{OA}$, Fransen PS, Beumer $\mathrm{D}$, et al. A randomized trial of intraarterial treatment for acute ischemic stroke. N Eng/ J Med 2015;372:11-20.

2 Jovin TG, Chamorro A, Cobo E, et al. Thrombectomy within 8 hours after symptom onset in ischemic stroke. N Engl J Med 2015;372:2296-306.

3 Saver JL, Goyal M, Bonafe A, et al. Stent-retriever thrombectomy after intravenous t-PA vs. t-PA alone in stroke. N Engl J Med 2015:372:2285-95.

4 Goyal M, Demchuk AM, Menon BK, et al. Randomized assessment of rapid endovascular treatment of ischemic stroke. N Engl J Med 2015;372:1019-30.

5 Campbell BC, Mitchell PJ, Kleinig TJ, et al. Endovascular therapy for ischemic stroke with perfusion-imaging selection. N Eng/ J Med 2015;372:1009-18.

6 Campbell BCV, Donnan GA, Lees KR, et al. Endovascular stent thrombectomy: the new standard of care for large vessel ischaemic stroke. Lancet Neurol 2015;14:846-54.

7 Powers WJ, Derdeyn CP, Biller J, et al. American Heart Association/American Stroke Association focused update of the 2013 guidelines for the early management of patients with acute ischemic stroke regarding endovascular treatment: a guideline for healthcare professionals from the American Heart Association/American Stroke Association. Stroke 2015:2015:3020-35.

8 Fiehler J, Cognard C, Gallitelli M, et al. European Recommendations on Organisation of Interventional Care in Acute Stroke (EROICAS). Int I Stroke 2016;11:701-16.

9 National Institute of Neurological Disorders and Stroke rt-PA Stroke Study Group. Tissue plasminogen activator for acute ischemic stroke. N Engl I Med 1995:333:1581-7.
10 Mistry EA, Mistry AM, Nakawah MO, et al. Systolic blood pressure within 24 hours after thrombectomy for acute ischemic stroke correlates with outcome. J Am Heart Assoc 2017;6:e006167

11 Goyal N, Tsivgoulis G, Pandhi A, et al. Blood pressure levels post mechanical thrombectomy and outcomes in large vessel occlusion strokes. Neurology 2017:89:540-7.

12 Tarlov N, Nien YL, Zaidat 00, et al. Periprocedural management of acute ischemic stroke intervention. Neurology 2012;79:S182-91.

13 Tsivgoulis G, Kotsis V, Giannopoulos S. Intravenous thrombolysis for acute ischaemic stroke: effective blood pressure control matters. Int I Stroke 2011;6:125-7.

14 Fischer U, Mattle HP. Blood pressure in acute stroke: still no answer for management. Stroke 2017:48:1717-9.

15 Oliveira-Filho J, Silva SC, Trabuco CC, et al. Detrimental effect of blood pressure reduction in the first 24 hours of acute stroke onset. Neurology 2003;61:1047-51.

16 Caplan LR, Hennerici M. Impaired clearance of emboli (washout) is an important link between hypoperfusion, embolism, and ischemic stroke. Arch Neurol 1998:55:1475-82.

17 Elijovich L, Goyal N, Mainali S, et al. CTA collateral score predicts infarct volume and clinical outcome after endovascular therapy for acute ischemic stroke: a retrospective chart review. J Neurointerv Surg 2016;8:559-62.

18 Goyal N, Tsivgoulis G, Nickele C, et al. Posterior circulation CT angiography collaterals predict outcome of endovascular acute ischemic stroke therapy for basilar artery occlusion. J Neurointerv Surg 2016;8:783-6.

19 Bhole R, Goyal N, Nearing K, et al. Implications of limiting mechanical thrombectomy to patients with emergent large vessel occlusion meeting top tier evidence criteria. J Neurointerv Surg 2017;9:225-8.

20 Goyal N, Tsivgoulis G, Iftikhar S, et al. Admission systolic blood pressure and outcomes in large vessel occlusion strokes treated with endovascular treatment. J Neurointerv Surg 2017;9:451-4.

21 Higashida RT, Furlan AJ, Roberts $\mathrm{H}$, et al. Trial design and reporting standards for intraarterial cerebral thrombolysis for acute ischemic stroke. Stroke 2003;34:e109-37.

22 Battey TW, Karki M, Singhal AB, et al. Brain edema predicts outcome after nonlacunar ischemic stroke. Stroke 2014;45:3643-8.

23 Goyal N, Tsivgoulis G, Pandhi A, et al. Admission hyperglycemia and outcomes in large vessel occlusion strokes treated with mechanical thrombectomy. J Neurointerv Surg 2017. doi: 10.1136/neurintsurg-2017-012993. [Epub ahead of print 13 Mar 2017].

24 Jauch EC, Saver JL, Adams HP, et al. Guidelines for the early management of patients with acute ischemic stroke: a guideline for healthcare professionals from the American Heart Association/American Stroke Association. Stroke 2013:44:870-947.

25 Wahlgren N, Ahmed N, Dávalos A, et al. Thrombolysis with alteplase for acute ischaemic stroke in the Safe Implementation of Thrombolysis in Stroke-Monitoring Study (SITS-MOST): an observational study. Lancet 2007;369:275-82.

26 Spiotta AM, Chaudry MI, Hui FK, et al. Evolution of thrombectomy approaches and devices for acute stroke: a technical review. J Neurointerv Surg 2015;7:2-7.

27 Goyal M, Menon BK, van Zwam WH, et al. Endovascular thrombectomy after large-vessel ischaemic stroke: a meta-analysis of individual patient data from five randomised trials. Lancet 2016;387:1723-31.

28 Liebeskind DS, Starkman S, Jo KD, et al. Blood pressure in acute stroke is inversely related to the extent of collaterals. Stroke 2008;39:538.

29 Castillo J, Leira R, García MM, et al. Blood pressure decrease during the acute phase of ischemic stroke is associated with brain injury and poor stroke outcome. Stroke 2004:35:520-6.

30 Leonardi-Bee J, Bath PM, Phillips SJ, et al. Blood pressure and clinical outcomes in the International Stroke Trial. Stroke 2002;33:1315-20.

31 Vemmos KN, Tsivgoulis G, Spengos K, et al. U-shaped relationship between mortality and admission blood pressure in patients with acute stroke. J Intern Med 2004;255:257-65.

32 Mulder M, Ergezen S, Lingsma HF, et al. Baseline blood pressure effect on the benefit and safety of intra-arterial treatment in MR CLEAN (Multicenter Randomized Clinical Trial of Endovascular Treatment of Acute Ischemic Stroke in the Netherlands). Stroke 2017:48:1869-76.

33 Martins Al, Sargento-Freitas J, Silva F, et al. Recanalization modulates association between blood pressure and functional outcome in acute ischemic stroke. Stroke 2016:47:1571-6. 